Article

\title{
Paris: Beyond the Climate Dead End through Pledge and Review?
}

\author{
Robert O. Keohane * and Michael Oppenheimer \\ Woodrow Wilson School of Public and International Affairs, Princeton University, Princeton, NJ 08544, USA; \\ E-Mails: rkeohane@princeton.edu (R.O.K.), omichael@princeton.edu (M.O.) \\ * Corresponding author
}

Submitted: 1 April 2016 | Accepted: 31 May 2016 | Published: 8 September 2016

\begin{abstract}
The Paris Climate Agreement of December 2015 marks a decisive break from the unsuccessful Kyoto regime. Instead of targets and timetables, it established a Pledge and Review system, under which states will offer Nationally Determined Contributions (INDCS) to reducing emissions that cause climate change. But this successful negotiation outcome was achieved at the price of vagueness of obligations and substantial discretion for governments. Many governments will be tempted to use the vagueness of the Paris Agreement, and the discretion that it permits, to limit the scope or intensity of their proposed actions. Whether Pledge and Review under the Paris Agreement will lead to effective action against climate change will therefore depend on the inclination both of OECD countries and newly industrializing countries to take costly actions, which for the OECD countries will include financial transfers to their poorer partners. Domestic politics will be crucial in determining the attitudes of both sets of countries to pay such costs. The actual impact of the Paris Agreement will depend on whether it can be used by domestic groups favoring climate action as a point of leverage in domestic politics - that is, in a "two-level game" simultaneously involving both international and domestic politics.
\end{abstract}

\section{Keywords}

climate change; climate cooperation; pledge and review; Paris agreement

\section{Issue}

This article is part of the issue "Climate Governance and the Paris Agreement", edited by Jon Hovi and Tora Skodvin (University of Oslo, Norway).

(C) 2016 by the authors; licensee Cogitatio (Lisbon, Portugal). This article is licensed under a Creative Commons Attribution 4.0 International License (CC BY).

\section{Introduction}

Climate change policy is a frustrating issue both for students of international cooperation and for scientists who have studied what is happening to the global climate system. Scientific evidence about the seriousness of the problem continues to accumulate but little effective action has been taken. However, at the $21^{\text {st }}$ Conference of Parties of the UN Framework Convention on Climate Change (UNFCCC), almost all the world's states agreed to a new Paris Agreement on Climate Change (2015). The purpose of this article is to provide a preliminary-and therefore tentativeassessment of the accomplishments achieved at Paris and the conditions under which the Paris Agreement can generate policies and actions that make a signifi- cant impact on global climate change.

Note that we don't ask whether the mere existence of the Paris Agreement will make a significant impact on global climate change. It won't. Such an international agreement can only be effective if it generates changes in the behavior of actors with resources that can be allocated and reallocated: that is, in the long term behavior of states, non-state actors such as business corporations, and individuals. A few such changes may occur because people recognize the severity of the climate issue, but most of them will come because leaders of states, publics, leaders of non-state actors, and billions of people have incentives-economic, political, or social-to do so. These incentives will be generated by political interactions in which states will play the leading roles, as well as in gradual normative shifts 
that influence individual behavior. We therefore focus in this article on the politics of climate change policy after the Paris Agreement, and in particular on the incentives faced by states and the strategies that they are likely to pursue.

For context, even given full implementation of the emissions reduction plans tabled at Paris (Intended Nationally Determined Contributions, see Section II) and continued pursuit of emissions reductions with the same level-of-effort throughout this century, avoidance of the benchmark two-degree warming would be very unlikely. However, the chances of a disastrous four-degree warming would shrink materially (Fawcett et al., 2015).

We begin in Section 2 by exploring the reasons for inaction so far on climate issues. Why has it been so difficult to make progress on this issue despite its severity and the threats it poses to ecological systems and human welfare? And how did these problems affect the negotiations surrounding the Kyoto Protocol to the UN Framework Convention on Climate Change (UNFCCC) and its fate after 1997? In Section 3 we will discuss the key provisions of the Paris Agreement, with some discussion of the political alignments observed during this process. Since the key innovation in approaches to the climate problem is the system of "Pledge and Review" instituted at Paris, we will focus our attention there. Section 4 of the paper will analyze climate politics post-Paris as a strategic game, in which outcomes result from an intersection of the strategies pursued by the various major players, in particular states. The conclusion will emphasize the main point: the Paris Agreement merely creates an opening for effective action on climate change. Political action by organized groups, domestic and transnational, will be essential to make Paris work; and this action will have to be accompanied by the willingness to pay the economic price.

\section{The Difficulty of Action on Climate Change and the Dead-End of Kyoto}

The Intergovernmental Panel on Climate Change has been convening natural scientists, economists, and other experts to write a comprehensive assessment report every 5-7 years since 1990. Each assessment has strengthened the message: anthropogenic climate change is significant, growing rapidly, and in many respects accelerating. Climate change poses a growing and in some respects an imminent threat not only to fragile ecosystems but to the livelihoods and lives of billions of human beings.

\subsection{Inherent Difficulties of Climate Change Action}

If the lack of an effective policy response to climate change seems strange in view of scientific findings, it is all too easy to understand from a political point of view. World politics is a decentralized realm, with no common government capable of deciding on a course of action and of implementing it through an organized hierarchy. Furthermore, climate change is a public bad. Almost all countries will suffer from climate changesome much more than others-but with the exception of a very few large entities, the future actions of each political unit will contribute only a negligible amount to its own suffering. So the incentives to ignore the climate externalities of one's own decisions - that is, to ignore the negative effects on others-are very large. Every country has an incentive to shirk, to free-ride on the efforts of others. In simplified form, the climate problem resembles the classic Prisoners Dilemma (Barrett, 2003), in which the option of not cooperating typically is more attractive than cooperation.

Compounding this difficulty is the issue of burdensharing. Any international agreement must pass a basic test of fairness, a reasonably equitable apportionment of the costs and benefits of implementation. The climate problem is plagued by multiple difficulties in determining what is fair: the disconnection created by the decades-long lags between costly emissions abatement and measurable reduction of climate impacts, the multiple frames for perceiving and assessing equity (e.g., total emissions, per capita emissions, historical emissions, national wealth), and the persistent scientific uncertainty in determining benefits to specific states and future generations that would accrue from near -term global action. Naturally, leaders and publics in each set of countries have distinctive conceptions of fairness, which often more or less coincide with their own interests in not accepting what seem to them disproportionate burdens. And countries and blocs have unequal power, deriving both from their different levels of emissions (making their participation more or less critical to an agreement) and from their different degrees of asymmetrical vulnerability to the actions of other states in domains other than climate (Keohane \& Nye, 1977).

International agreements have been feasible, and international institutions have had some impact, on a wide variety of issues, ranging from trade to human rights. These are also difficult issues, implicating entrenched economic interests and threatening the political control of governments. Some of them involve global public goods. Notably, the Montreal Protocol on Substances that Deplete the Ozone Layer was negotiated in 1987 , went into force at the beginning of 1989 , and is already having a marked impact on the ozone layer. "Why," one could ask, "is climate change any harder?"

The answer to this question begins by recognizing two key variables that affect the efficacy of global institutions: the benefits and costs of cooperation, on the one hand, and whether the agreement can be enforced, on the other. The ratio of benefits to costs is obviously important: the higher the ratio, the more the incentive to find some way to collaborate in order to 
secure these gains. This will be true of states, subnational governments, firms, and individuals. But the absolute level of costs is also important, since cooperation is risky, and when costs are high, states undertaking costly action risk being seriously disadvantaged if their partners do not fulfill their side of the agreement.

Due to the decentralization of world politics, hierarchical enforcement of agreements through global government is not feasible. To effectively bind states, agreements must be self-enforcing. Grundig, Hovi, Underdal and Aakre (2012, p. 527), drawing on work by Barrett (1994) and Telser (1980), have defined selfenforcing agreements in terms of three conditions: “1) no member can benefit by withdrawing; 2) no member can benefit by being noncompliant; 3) conditions 1 and 2 hold without external enforcement." An example of external enforcement, rare in world politics, would be UN Security Council enforcement of a resolution passed under Chapter VII of the United Nations Charter such as sanctions against Iraq in the 1990s or North Korea now.

Some self-enforcing agreements pertain essentially to coordination games, like the common understanding in the United States that one drives on the right-hand side of the road or many industrial standard-setting arrangements. Once an equilibrium is reached, parties have no incentive to deviate from it. But with respect to many other agreements, including major climate change agreements, participants have an incentive to do as little as possible, thereby reaping gains from others' contributions (Keohane \& Victor, 2016). For such agreements to be self-enforcing, reciprocity typically needs to be part of the process. Reciprocity involves contingent exchanges so that failure to meet one's obligation by one party can be expected to lead to adverse actions by its partners. As a result, the benefits that each partner receives from the interaction tend to depend on its own performance (Keohane, 1986).

Global negotiations are typically characterized by reciprocity: bargaining inherently involves exchanges of promises, or commitments, so that each party's concessions are matched with gains from the concessions of others. This form of reciprocity is as important in generating climate change agreements as in other international negotiations. But reciprocity is even more important at the enforcement stage: in this form of reciprocity, states that fail to fulfill their commitments face withdrawal by others.

Trade agreements typically rest on such enforcement reciprocity: a state that violates World Trade Organization (WTO) rules can be punished by withdrawal of the benefits it receives from the WTO. Indeed, the adjudication institutions of the WTO are designed to facilitate such enforcement reciprocity. Similar processes are observed on other issues. Failure to abide by aviation safety and security rules may be punished by withdrawal of landing privileges, or refusal by airlines to fly into certain destinations. Reneging on debts, or expropriating private property without compensation, often entails penalties, either in accordance with international agreements or simply by abstaining from future investments. In situations like these, states have incentives to withhold benefits from treaty partners that renege on their agreements, since their domestic interests will have suffered from reneging and are likely to support action. Exporters will support trade retaliation insofar as its purpose is to deter protection by others that adversely affects them, airlines will avoid flying into dangerous airspace, and investors are likely to shun jurisdictions with a record of expropriation without compensation. As a result, when the goods being exchanged provide specific and easily identifiable benefits for particular countries and interests, enforcement reciprocity will be specific and relatively easy to implement, and is likely to be effective.

Other factors may also affect support for global institutions. For instance, sometimes the symbolism of multilateral agreements is so important that it can be used by political actors, usually operating at the domestic level, to achieve outcomes in line with the agreements' objectives. Human rights institutions do not rest on reciprocity, are not enforceable, and their rules are frequently violated. But they are not costly to their sponsors, and groups within countries where human rights are contested can sometimes use these institutions as "hooks" to grab onto, calling attention to international norms and seeking to shame their compatriots into conforming more closely to them (Simmons, 2009). These efforts are not always successful, but the international norms provide some leverage for domestic political actors. Sometimes a norm is so pervasive and strong that it turns an activity into a taboo (e.g., slavery), making adherence to international agreements easier although still not necessarily universal (Keck \& Sikkink, 1998). The practice of international election monitoring provides another case in point: the result may be "D-elections" rather than failures (Kelley, 2009), but there is often some impact. Climate change has considerable symbolic importance, which could enhance the likelihood that domestic political actors would use international climate change norms effectively to influence domestic politics.

When institutions involving global public goods are concerned, it is difficult to employ enforcement reciprocity directly: the good (such as less climate change) cannot be withheld from free riders precisely because it is public. Sometimes enforcement reciprocity can be provided through sanctions, especially trade sanctions, but such sanctions will not only damage their targets but will also harm importing or exporting interests at home in the short term. Although as noted above, exporters may support such sanctions for reasons of deterrence, they may be inhibited from doing so by the short-term costs. Finally, providing public goods can 
have symbolic benefits for providers; but these benefits are only likely to make an impact when material costs are low. For instance, it turned out that the Montreal Protocol was not costly to states: cheap substitutes for the offending ozone-depleting chemicals were rapidly found. Furthermore, the favorable benefit-cost ratio of Montreal provided incentives for governments to threaten trade sanctions against states that violated its provisions-and since potentially noncomplying or non-participating states were few and the costs of sanctions low, these threats were effective. And the costs of monitoring compliance were low as well.

Unfortunately for efforts to protect the global climate, actions to reduce climate change are costly, requiring major changes in carbon-based economies. If technological progress continues rapidly, these costs should not be so great as to require major changes in life-styles, but they will be considerable, and will require a shift of resources toward climate action, leading to higher energy costs, higher taxes, and probably reduced services to citizens. For example, the IPCC calculates that a cumulative reduction in global consumption of $3-11 \%$ by 2100 is necessary to achieve an emissions pathway which has a high probability of avoiding a two-degree warming, the currently accepted benchmark for a dangerous warming (IPCC AR5, 2014, WGIII Figure SPM.2). Accepting the costs of actions to limit climate change will be difficult for democratic publics and unpopular with authoritarian leaders striving to gain in wealth and power. States will therefore seek when possible to employ bargaining power to shift these costs onto others. Reciprocity will be essential to making agreements self-enforcing but will be difficult to implement.

\subsection{Pathologies of the Kyoto Process}

The inherent difficulty of slowing climate change and eventually stabilizing the climate has discouraged states from taking costly actions on this issue, since it has seemed doubtful that others will follow. In addition, the structural problems we have mentioned have been compounded by differences among countries in the costs of action, as a result of diverse energy mixes and endowments, and differential views on impacts and adaptation possibilities. For instance, pathways characterized by stringent emissions reduction would result in reductions in investment in fossil fuel extraction of about \$0-90B for OECD countries vs \$0-280B for non-OECD countries per year for the period 20102029 while requiring increases in annual investments in energy efficiency of about \$0-300B and \$0-330B for OECD and non-OECD countries respectively over the same period (IPCC AR5 WGIII Figure TS-39). Not only do these potentially massive shifts bear significant implications for the relative status of domestic interests and for the relative economic position of each country vs others. They also reveal the huge uncertainties that decision makers face.

As a result, only the European Union (EU) - whose publics were most committed and whose political systems included Green parties either in government or contending for power-was willing to take the lead. In the Kyoto agreement, the EU offered a larger percentage reduction from 1990 levels than the United States or other OECD countries-although using 1990 enabled it to incorporate emissions-heavy East Germany in its baseline while the US was faced with a projection of more rapid emissions growth above the 1990 baseline. But in recent negotiations, since the EU was already committed to very large reductions in emissions, it had little reciprocity-based leverage in bargaining with other countries and groups. Due to domestic politics, and in contrast to many countries, the EU cannot credibly threaten to do less in response to non-performance by others.

International cooperation is typically slow and incremental, reflecting governments' unwillingness to commit substantial resources without an assurance of a supportive coalition. But such incremental action can have a substantial impact over time insofar as it builds on past achievements. The World Trade Organization, for instance, built on the General Agreements on Tariffs and Trade, which also pushed toward liberal trade policy and was also rooted in reciprocity, but which did not have the dispute settlement provisions established under the WTO. However, in the climate change arena previous agreements did not provide a firm foundation for incremental progress. On the contrary, they incorporated three fatal flaws that generated a dead-end instead of a foundation for progress.

The first flaw was that no agreement was ever reached in the UNFCCC process on how to utilize voting to decide issues, so the default rule of consensus was used. Naturally, this rule gave disproportionate power in the decision-making process to states that sought to block or disrupt the effective action, even if they were small and weak. In Copenhagen in 2009, a proposed final document was blocked by a small number of opposing states, none of which was a major emitter.

The second flaw was that the Kyoto Protocol relied on a "top-down" model of targets and timetables. At the 1997 meeting in Kyoto that produced the Protocol, states had agreed to specific emissions reductions, using 1990 as a base year and extending out to the end of an initial commitment period in 2012 . These reductions were meant only as a first step and were not intended to be sufficiently steep to halt anthropogenic climate change. But they were generated through an international negotiating process that had little input from domestic politics, and they were quite precise. As a result, the United States refused to ratify the Protocol; Russia held out opportunistically for favorable treatment on other international issues when its adherence 
became crucial to Kyoto's entry into force; Australia delayed ratification for ten years despite a favorable emissions allotment compared to other OECD countries; and some ratifying countries, notably Canada, failed to comply with their commitments or even to come close (and Canada eventually withdrew from the Kyoto Protocol).

The third flaw was that the UNFCCC process, as specified in the Berlin Mandate of 1995 and institutionalized in the Kyoto Protocol, exempted developing countries from any emissions reduction obligations. In this respect, Kyoto was a step backward from Montreal, which had included developing countries under its mandatory provisions reducing production of ozonedepleting substances but had allowed them much more time to meet the obligations and offered them financial compensation for doing so. Yet it turned out that major developing countries such as China and India grew rapidly after 1995 and therefore quickly became major sources of annual emissions. The exemption of developing countries-with China becoming a major exporter of goods to the United States-became a key reason for the reluctance of the United States to ratify the Protocol. Kyoto therefore accomplished the perverse double trick of imposing politically unsustainable burdens on wealthy democracies while avoiding putting any constraints on countries that were becoming major sources of emissions and were their trade competitors (Victor, 2011).

For these reasons, by 2010, after the unsuccessful Copenhagen conference of 2009, it had become clear that Kyoto, though not necessarily the UNFCCC, was a dead-end.

\section{Pledge and Review at Paris and in the Future}

Instead of trying to confront the realities of international climate change policy head-on, as Kyoto did, the Paris Agreement represents an "end-run" around these constraints, using discretion and vagueness rather than mandates and simplicity.

\subsection{Discretion and Vagueness}

Discretion was incorporated into the negotiation process at COP19 in 2013, by deciding that each state was to submit its Intended Nationally Determined Contribution, specifying what it intended to do. As of December $15,2015,160$ submissions, covering 187 countries accounting for $95 \%$ of total global greenhouse gas emissions, had been submitted, with the remainder of emissions coming from bunker fuels and from countries not part of the UNFCCC (Climate Tracker, March 14, 2016). Each state could submit INDCs of whatever format and detail they preferred. As a result, INDCs present a wide variety of levels of ambition and types of action; so it was virtually impossible to refuse to submit them. All states had at minimum an interest in an agreement in Paris that would validate their INDCs as acceptable opening bids. The incentives were therefore the opposite of those facing states whose negotiators had agreed to Kyoto targets and timetables, which might possibly be difficult to meet and (even without credible enforcement arrangements) embarrassing to miss. At Paris, it would have been embarrassing not to submit an INDC.

Such discretion was clearly advantageous for facilitating negotiations, since the most contentious issue of all-how to share the international emissions reduction burden corresponding to avoidance of a dangerous climate change- was simply not grappled with, nor was any date for this reckoning set. (This burdensharing problem can be viewed, equivalently as the problem of how to allocate the limited remaining emissions headroom between today's atmospheric levels of greenhouse gases and that corresponding to a twodegree warming.) Postponing a decision on this crucial issue could be viewed as the ultimate act of kickingthe-can-down-the road, enabling politicians to avoid paying the cost of their declared commitment to moving toward a stable global climate. But in view of the political constraints at Paris it was an essential decision that needed to be made for some progress to take place. We should not, however, pretend that the problem was by any means solved; we can only hope that the next few years will be used well, enabling technologies, practices, and international relationships to adjust to an emissions-constrained world.

The INDCs range from ambitious in terms of what states may be reasonably able to achieve given focused national action to resembling business-as-usual, that is, requiring little additional effort. They also span a range from being highly specific about actions needed to being disturbingly vague. The US INDC is very specific in term of regulatory actions and some observers regard it as highly ambitious, especially given the contentious US political scene. With China's carbon dioxide emissions from fossil fuel combustion apparently decreasing between 2014 and 2015 (Jackson et al., 2015) and coal use probably having peaked, its plan may not be highly ambitious but it is, like the US plan, very specific as to anticipated actions. Russia's plan is neither ambitious nor specific. For states having the capacity to forecast emissions and implement policies to influence their economic development, these diverse approaches to INDCs are strategic choices that bear implications for the outcomes discussed in Section 4.

National discretion also enabled countries to develop their INDCs in a manner that enabled them to respond to the interests and views of domestic constituencies. Their implementation is therefore likely to be somewhat easier than otherwise, and seems unlikely to face the same level of domestic opposition that resulted in the refusal of the United States to ratify the Kyoto Protocol and Canada's withdrawal from its Kyoto 
commitments. When a state submits its instrument of ratification, its INDC's become its "Nationally Determined Contributions" (NDCs) unless superseded by an updated filing. Some NDCs (particularly those of China and the US) are already well along in implementation.

Another feature of the Pledge and Review process that was attractive both to governments that were reluctant to make commitments, and to governments uncertain about their ability to meet targets, was its vagueness. For instance, there is no binding obligation actually to implement the plans indicated in the NDCs. Article 4, paragraph 2, of the Paris Agreement states as follows: "Each Party shall prepare, communicate and maintain successive nationally determined contributions that it intends to achieve. Parties shall pursue domestic mitigation measures, with the aim of achieving the objectives of such contributions" (emphasis ours). The 'aim of' phrase is reminiscent of language in Article 4 of the original UNFCCC in 1992 that turned out to be entirely ineffective. Furthermore, the key Pledge and Review provisions in Articles 13 (on transparency) and 14 (periodic review) are also vague.

Article 14 is short and merely provides for a global stocktaking of implementation every five years beginning in 2023. The first three paragraphs of Article 13 emphasize the flexibility of the process as opposed to demands placed on states. Most of the remaining ten paragraphs provide general justifications for transparency (Paragraphs 5 and 6), general statements about decision-making (Paragraph 4), instructions or requests to states to provide information (Paragraphs 7-10), or discussions of the technical expert reviews of information provided by states (Paragraphs 11-12). Even the requests for information in Paragraphs 9 and 10 differentiate between developed country Parties, which "shall" provide information, and developing country Parties, which "should" do so. The last two paragraphs (14 and 15) emphasize the support to be provided for developing countries to implement Article 13. Finally, the key procedural provision for transparency procedures (Paragraph 13) does not specify such procedures but is only an injunction to the Conference of Parties itself to make a decision in the future. In other words, Article 13 elevates vagueness to an art form.

Pledge and Review will only work if there is transparency, so that governments have a reputational stake in taking costly actions; otherwise we can expect a pattern of unobserved reneging, accompanied by misleading governmental statements. Yet there is no strong textual or legal basis for confidence that transparency will be implemented or that Pledge and Review will therefore be important. The value of the Pledge and Review process will therefore depend on whether governments make it more transparent and demanding; and these actions will depend on the incentives that they face. To assess the value of COP 21, therefore, we need to analyze these incentives.

\subsection{Incentives for Governments for Transparency or Opaqueness}

Governments have many demands on them, and always have constrained resources. Whether democratic or not, they respond to pressure from influential interest groups. So why should they act on climate change? Apart from a sense of altruism toward future generations on the part of societies or their leaders, five specific purposes can be distinguished:

1) To achieve domestic purposes, such as to reduce air pollution (including soot/black carbon) emissions or to achieve energy system changes that are not directly related to climate change;

2) To respond to pressure from domestic constituencies. If such pressure is sufficiently strong, domestic motivations are sufficient and internationally-based incentives to act are redundant;

3) To gain specific benefits from other statesespecially in this case, specific reciprocity in terms of greenhouse gas reductions;

4) To gain diffuse benefits from other states and perhaps from civil society elsewhere. For example, if a small state supports a climate change treaty that is strongly endorsed by the United States and China, it could expect to receive a more sympathetic hearing for its own requests of these great powers for aid or diplomatic support than if it opposed such a treaty;

5) To impress domestic constituencies, or avoid blame, by cultivating international reputation, or otherwise to leverage international negotiations for domestic political purposes, as in our discussion of two-level games below.

Agreeing to Paris was consistent with these incentives for all 187 states submitting INDCs because the agreement places only modest burdens on states and, as we have seen, is vague at key points. The symbolic reputational gain of adherence, and the advantage of having one's own non-enforceable pledges acknowledged in the agreement, exceeded the costs. On the other side of the ledger, the reputational costs of opposition would have been high for most states.

The same reputational logic does not apply to forthcoming decisions: specifying what Article 13 on Pledge and Review means and following up by fostering transparency; meeting the NDC targets and enhancing targets progressively as called for in the Agreement. Unlike the promises incorporated in the NDCs, these decisions will be costly. How will governments think about them?

\section{Post-Paris Climate Politics as a Two-Level Game}

What the Paris Agreement will lead to is uncertain, 
since its provisions are so vague and many decisions on making them more specific will be the result of a decentralized political process. But what is certain is that climate outcomes after Paris will follow from what can be characterized as a "two-level game" (Putnam, 1988), involving a combination of international strategic interaction and domestic politics. One level is that of international negotiation; the other level pertains to coalition-building in domestic politics.

One way of thinking about such a situation - which admittedly simplifies but may also clarify-is to begin by analyzing it as a strategic game with a limited number of key actors. In deciding on the specific provisions for Pledge and Review, states will be crucial; so we can begin with an interstate game, with three types of players, each type having a distinctive strategy. In reality, none of these three groups is unified: individual countries within each of the three types of players have somewhat different interests, and even when their interests overlap, they may have difficulty concerting policy with one another, partly because they compete in policy dimensions other than climate. And we do not mean to imply that the negotiations that will take place all occur within the framework of the COP meetings. Many of them will take place in meetings of groups such as the G-20, and even more may be bilateral or "minilateral," involving a small number of countries. And some bargaining is implicit.

Committed governments in OECD countries need to act in a way that enhances their ability to persuade other states to make commitments, principally through negotiation reciprocity-tit for tat bargaining. But they also must maintain or bolster domestic support, and for their long-term commitments to be credible they need to limit the freedom of action of future governments of their own countries. Yet they are constrained by the public goods nature of the problem: as we have seen, climate agreements cannot be enforced through simple reciprocity, involving threats or actions to stop reducing one's own emissions. Instead, enforcement reciprocity must be indirect, through sanctions on trade or financial flows, which may widen the sphere of conflict as well as generating domestic opposition from affected interests. So maintaining domestic support for costly climate change actions that go beyond what the state would do in the absence of an agreement is not easy.

Governments of major emerging market countries (BRICS) are affected by climate change and therefore have some reason to act on these issues, and they may have domestic groups that favor action, either because they are concerned about climate change or because they see industrial opportunities-for example, the construction of solar panels in China-arising from global action. Their interest in climate change action varies; India and Russia are notably more reluctant to act than Brazil and China. Yet all of them want other states, in particular the major OECD countries, to act, and they know that OECD actions will depend on their own commitments. But the principal focus of BRIC governments is economic growth. And they want to minimize costs for themselves and to maximize flexibility in fulfilling their own commitments. They therefore find themselves in a negotiation reciprocity game, seeking to do enough to induce action by others and avoid sanctions against themselves, but not so much that they bear heavy burdens that seriously affect economic growth or reduce domestic public support for the ruling group. Some BRIC countries also seek financial and technological assistance, which will help to relax their own domestic constraints.

Finally, governments in small, poor states have an interest in free riding without detection or at least punishment. Their major liability is that they lack the capacity to influence the policies of powerful states; but their corresponding advantage is that no one can expect them to contribute much, except symbolically, to solving the climate problem. They are therefore unlikely to be the principal targets of committed states and non-state actors seeking to ensure that climate agreements are effective. These small, poor states will seek a Pledge and Review scheme that is focused on the major polluters and that provides flexibility in the demands imposed on them and monetary compensation in one form or another-once again, to maintain domestic support as well as to achieve a variety of other objectives.

In this perspective, the critical question is whether there is a zone of agreement that would be beneficial, compared to the status quo of no agreement and independent national action, in these three sets of interactions.

The two most important negotiating assets of rich OECD countries are their ability to limit, or fail to limit, their emissions and their willingness to provide financial and technical assistance. The BRICs' most important negotiating asset is generated by their huge current and prospective emissions and their ability to decide to what extent to reduce them. The poor countries' chief asset is their ability to appeal to the principle of fairness and, if they are unsatisfied, to deny legitimacy to any deals that are made.

All sources of leverage are constrained by domestic politics. A critical factor, therefore, in whether a zone of agreement for specific Pledge and Review provisions will be reached, is how strongly domestic publics and elites-whose relative importance varies with the political system of the country-will support expensive measures designed to reduce climate change. As usual, domestic politics is crucial in determining whether multilateral institutions can be effective.

The OECD countries need the BRICs to accept relatively tight limits on their emissions, such that their growth in emissions stops within ten or fifteen years and their absolute emissions curves turn downward 
shortly thereafter. Policies of the BRICs vary considerably so it is a deliberate oversimplification to treat them as a bloc for the sake of analysis. For example, China's Paris commitment, largely embodied in its 2014 bilateral agreement with the United States, foresees an emissions peak by 2030 . This is not a difficult target for China, given that many observers believe that China actually reached it in 2014 after a period of extraordinarily rapid emissions growth. India, which has been slower than China to adopt serious emissions reductions, now looms as the most important new source of rapid emissions growth. OECD countries hope to see a rapid turnaround not only by BRICs but also by other countries whose economies similarly emerge over time (Richels, Rose, Blanford, \& Rutherford, 2015). The BRIC countries' willingness to accept clear procedures for Pledge and Review, with expectations of enhanced pledges on their own parts along with provisions for transparency, will depend on their willingness to accept such objectives. Their basic decisions on this issue will depend in the first instance on their own calculations about their own interests. Apart from concessions they receive from the OECD countries, what will be the costs (especially to economic growth) of action, on the one hand, compared to climate-related costs of inaction, on the other?

Since climate change is a public goods problem, we know that these calculations alone will not yield vigorous action on emissions limitations by the BRICs. They will need concessions of three types by the OECD countries: on emissions, on technical assistances, and on financial aid. That is, the BRICs will calculate what their prospective willingness to accede to strict Pledge and Review procedures will gain them in negotiations with the OECD countries. They will seek to assure that their current competitive economic advantages over the OECD countries are not sacrificed in a climate agreement and that they are offered access to markets for new climate change-related products that they would have a comparative advantage in making. It follows that an OECD-BRIC climate agreement will turn on how forthcoming the OECD countries will be about emissions limits, technical assistance, flexibility on trade (such as the emerging agreement of trade in green goods and services), and financial aid.

For the OECD-poor country negotiations, the game is simpler. The OECD countries needed the consent of poor countries to the Paris Agreement, due to UNFCCC rules, but it is not very important to them what the small, poor countries actually do, since their emissions are so small. They need these countries not flagrantly to increase emissions, in a way that leads BRICs to do the same. For their part, the poor countries seek to avoid being targets of sanctions by OECD countries, and to obtain more funding for adaptation and technical aid. They would also like to have an amplified "loss and damage" provision, but since the large- emitter countries adamantly resisted such a commitment at Paris and in fact imposed a ban on liability or compensation from damages in this context, any such deal will instead emphasize adaptation funding. A deal between the OECD countries and the small, poor countries that provides for lax reporting requirements (already foreshadowed in language agreed at Paris) and substantial adaptation aid seems feasible. These concessions would be justified by the low incomes, and state capacity, of these poor countries.

At the moment, the BRICs-poor country bargaining game is the least important, since the poor countriesreluctant to make costly commitments themselves-are therefore disinclined to press the BRICs to reduce emissions; and the BRICs (with the exception of China) are only reaching the point of being able to give sufficient financial aid to induce greater effort from the poor countries. As the BRICs become richer, this bargaining game is likely to become more important, insofar as the BRICs take mitigating climate change seriously.

If the OECD countries are sufficiently committed to slowing and stopping climate change, there seems to be room for OECD-BRIC and OECD-poor country deals that, in both strategic games, make both parties better off than in the status quo. The OECD countries would secure some otherwise unavailable contributions to reducing emissions-some of which can be reduced relatively cheaply in the BRICs and poor countries. The BRICs and poor countries would gain technical and/or financial benefits that are easier for the OECD states to provide than for the BRICs and poor countries to generate for themselves.

What is less clear is whether the resulting deals will enhance the effectiveness of the COP-21 Pledge and Review process in helping the world limit climate change. We can imagine high-level equilibria of these games that would do so. These equilibria would induce substantial cuts in emissions by the BRICs and would avoid explicit and coordinated opposition to the agreement by poor countries. They will be costly for OECD countries and their domestic publics but their costs may be spread over a diverse set of objectives, both climate and non-climate. At the same time, cooperative mechanisms for achieving these multiple objectives may operate in a range of venues, for example current negotiations under the Chicago Convention to reduce emissions from aviation and under the Montreal Protocol, to control production of hydrofluorocarbons (Stewart, Oppenheimer, \& Rudyk, 2015). Finally, finding a satisfactory equilibrium will depend heavily on technological progress aimed at moderating the cost of alternative energy.

We can also imagine low-level equilibria: an OECDBRIC deal that enables both sides to pursue essentially business as usual under the cover of an agreement (thereby protecting their reputations) and an OECDpoor country deal that essentially exempts poor coun- 
tries from effective emissions reductions. In such a low-level equilibrium, poor countries and some of the BRICs will pretend to combat climate change and the rich countries will pretend to pay them for doing so.

What is clear is that whether negotiations lead to substantial emissions cuts will not depend chiefly on the text of the Paris Agreement. It will depend much more on domestic and transnational politics within and between the OECD countries and the BRICs. This is to say that by itself the Paris Agreement accomplishes littlebut it opens what was a locked door. That door is now a little bit ajar -pushing hard could carry us through it to a better outcome, but nothing will be accomplished at the international negotiation level alone. There will have to be pressure within the OECD countries for vigorous emissions action by wealthy states and for financial support for effective action in poorer countries. And that pressure will have to entail willingness to pay.

\section{Conclusion: Climate Change Politics and Transnational Civil Society}

The Paris Agreement is less an accomplishment than part of an ongoing process. It opens the door to progress on climate but does not assure it. For Pledge and Review to work there will have to be clear expectations that pledges will be regularly upgraded, and substantial transparency so that compliance with pledges can be monitored. There may also have to be willingness on the part of those countries most committed to climate change to punish those states that fail to make serious commitments or renege-although as we have seen, such enforcement reciprocity is difficult on issues involving public goods.

We have emphasized the importance of domestic politics in affecting the outcomes of the interstate strategic games on climate change policy. But in the era of the internet and social media, domestic politics is closely linked to transnational interactions. Transnational movements and organizations can play an important role in mobilizing support within countries for costly climate change action. Such movements will be most important not when they simply point to the failure of others-their targets-to support climate change action, but when they mobilize support for costly action by their own supporters, and the countries in which they are based.

For the Paris Agreement to put the world on a path toward limiting climate change to acceptable levels, publics, organized and mobilized in many countries and transnationally, will need to act politically, and will need to make their political actions credible by being willing to pay the necessary economic price.

\section{Acknowledgments}

The authors express their thanks to the editors of this volume and two anonymous referees for perceptive comments that were valuable in making revisions to our original draft.

\section{Conflict of Interests}

The authors declare no conflict of interests.

\section{References}

Barrett, S. (1994). Self-enforcing international environmental agreements. Oxford Economic Papers, 46(1), 878-894.

Barrett, S. (2003). Environment and statecraft. Oxford: Oxford University Press.

Fawcett, A. A., Gokul, C. I., Clarke, L. E., Edmonds, J. A., Hultman, N. E., McJeon, . . Shi, W. (2015). Can Paris pledges avert severe climate change? Science, 350, 1168-1169.

Grundig, F., Hovi, J., Underdal, A., \& Aakre, S. (2012). Self-enforcing peace and environmental agreements: Toward scholarly cross-fertilization? International Studies Review, 14, 522-540.

IPCC AR5. (2014). Intergovernmental Panel on Climate Change (IPCC) synthesis report 2014 (AR5) (Fifth assessment report of the Intergovernmental Panel on Climate Change, Working Groups I, II, and III). Geneva, Switzerland: UN.

Jackson, R. B., Canadell, J. G., Le Quéré, C., Andrew, R. M., Korsbakken, J. I., Peters, G. P., \& Nakicenovic, N. (2016). Reaching peak emissions. Nature Climate Change, 6, 7-10.

Keck, M., \& Sikkink, K. (1998). Activists beyond borders. Ithaca: Cornell University Press.

Kelley, J. (2009). D-minus elections: The politics and norms of international election observation. International Organization, 63(4), 765-788.

Keohane, R. O. (1986). Reciprocity in international relations. International Organization, 40(1), 1-27.

Keohane, R. O., Nye, Jr., J. S. (1977). Power and interdependence. Boston: Little, Brown.

Keohane, R. O., \& Victor, D. G. 2016. Cooperation and discord in global climate Policy. Nature Climate Change, 6, 570-575.

Paris Agreement on Climate Change (2015). Adopted text. UNFCCC/CP/2015/L.9rev.1. Paris, France, December 12, 2015.

Putnam, R. D. (1988). Diplomacy and domestic politics: The logic of two-level games. International Organization, 42(3), 427-460.

Richels, R., Rose, S., Blanford, G., \& Rutherford, T. (2015). Limiting global warming. Presented at COP21, Paris, December 10.

Simmons, B. (2009). Mobilizing for human rights: International law in domestic politics. New York: Cambridge University Press.

Stewart, R. B., Oppenheimer, M, \& Rudyk, B. R. (2015). A 
building blocks strategy for global climate change. In S. Barrett, C. Carraro, \& J. de Melo (Eds.), Towards a workable and effective climate regime. London: CEPR Press. Retrieved from voxeu.org/content/ towards-workable-and-effective-climate-regime
Telser, L. G. (1980). A theory of self-enforcing agreements. The Journal of Business, 53(1), 27-44.

Victor, D. G. (2011). Global warming gridlock. New York: Cambridge University Press.

\section{About the Authors}

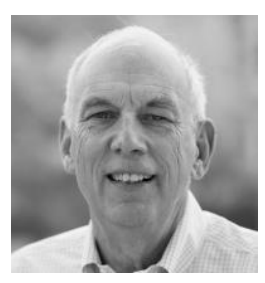

Robert O. Keohane, a political scientist, is Professor of Public and International Affairs in the Woodrow Wilson School at Princeton University. He is author of After Hegemony: Cooperation and Discord in the World Political Economy (1984), and co-author of Power and Interdependence (with Joseph S. Nye, Jr., 1977), and Designing Social Inquiry (with Gary King and Sidney Verba, 1994). He is a member of the National Academy of Sciences (US) and a Corresponding Fellow of the British Academy.

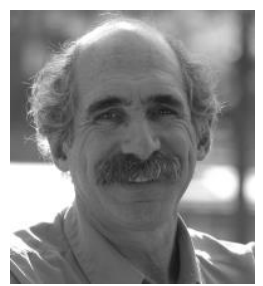

Michael Oppenheimer, a climate scientist, is the Albert G. Milbank Professor of Geosciences and International Affairs in the Woodrow Wilson School and the Department of Geosciences at Princeton University. His involvement with climate negotiations began when he participated in and coorganized a series of international science-and-policy conferences in the mid-1980s that pressed for development of a climate convention. He is credited with various levels of authorship of each of the five IPCC assessments, including as coordinating lead author of the Fifth Assessment Report. 